\title{
Stress, Burnout, and Coping among First-Year Medical Undergraduates
}

\author{
Naresh Nebhinani ${ }^{1}$ Pooja Patnaik Kuppili², Mamta $^{3}$ \\ ${ }^{1}$ Department of Psychiatry, All India Institute of Medical Sciences, \\ Jodhpur, Rajasthan, India \\ ${ }^{2}$ Black Country Healthcare Foundation NHS Trust, Wolverhampton, \\ United Kingdom \\ ${ }^{3}$ College of Nursing, All India Institute of Medical Sciences, Jodhpur, \\ Rajasthan, India \\ Address for correspondence Naresh Nebhinani, MD, DNB, \\ Department of Psychiatry, All India Institute of Medical Sciences, \\ Jodhpur, Rajasthan, India (e-mail: drnaresh_pgi@yahoo.com).
}

J Neurosci Rural Pract 2021;12:483-489.

Background and Objectives Stress, burnout, and coping have been found to be interlinked with each other. Several adverse psychological outcomes have been associated with stress and burnout. Improving coping can decrease the stress and burnout. There is limited literature on perceived stress, coping, and burnout among first-year medical undergraduates from India. With this background, the study aimed to assess perceived stress, coping, and burnout among first-year medical undergraduates.

Methods It was a cross-sectional study assessing 100 undergraduates studying in the first year of medical school. Medical Students Stressor Questionnaire, Brief COPE questionnaire, and Maslach burnout inventory-student survey were applied for assessment of perceived stress, burnout, and coping, respectively. Socio-demographic profile was assessed by a semi-structured proforma.

Results Majority of students reported facing moderate level of stress in most of the domains, with stress being the highest for the academic aspects and least for social-related and drive- and desire-related areas. The stress was significantly greater in female students. Burnout was identified in $62 \%$ students by two-dimensional criteria and $30 \%$ by three-dimensional criteria. Among the coping strategies, active coping was most commonly used and substance use was less commonly used. No differences were found in coping between males and females except for active coping, which was significantly better in females.

Conclusion The stress was of moderate degree in majority of students and academic stress was the most common stress. Burnout was present in at least one-third of the students. However, majority of the students practiced active coping.

\section{Key Messages}

- Majority of the medical undergraduates in the first-year experience moderate stress.

- Perceived stress is higher in females than males.

- Burnout is noted in about one-third of medical undergraduates in first year.

- Active coping is practiced by majority of the medical students.

published online

May 10, 2021
DoI https://doi.org/

$10.1055 / \mathrm{s}-0041-1727576$

ISSN 0976-3147

\section{Introduction}

Stress can be considered analogous to a double-edged sword. Whereas "eustress" can lead to better performance, pathological forms of stress or distress is found to be associated with adverse mental health outcomes as depression, anxiety, self-harm, insomnia, burnout, maladaptive coping such as substance use, suicides, as well as poor quality of

(c) 2021. Association for Helping Neurosurgical Sick People.

This is an open access article published by Thieme under the terms of the Creative Commons Attribution-NonDerivative-NonCommercial-License, permitting copying and reproduction so long as the original work is given appropriate credit. Contents may not be used for commercial purposes, or adapted, remixed, transformed or built upon. (https://creativecommons.org/licenses/by-nc-nd/4.0/).

Thieme Medical and Scientific Publishers Pvt. Ltd. A-12, 2nd Floor, Sector 2, Noida-201301 UP, India 
life and academic performance. ${ }^{1,2}$ Medical education is found to be more stressful than nonmedical branches of education. ${ }^{3}$ Furthermore, first-year medical students have unique challenges when compared with other years of medical education as they begin their foray into the medical academia. Transition from adolescence to adulthood, exposure to newer curriculum and variation in teaching methods, mismatch between expectation and demands of medical school are some of the issues they begin to face.

Stress, burnout, and coping are found to be interlinked with each other. The prevalence of stress and burnout ranged from $\sim 21$ to $90 \%$ and 27 to $75 \%$, respectively, in preclinical medical students. ${ }^{4}$ Self-efficacy, resilient way of coping, and optimism were found to affect perceived stress and further modulated anxiety and depression in first-year medical students. ${ }^{5}$ Improving "Coping Reservoir," that is, personality characteristics and style of coping, can decrease distress and burnout. ${ }^{6}$ Perceived stress was associated with burnout and inversely associated with active coping in final-year undergraduate medical students as well as medical postgraduate students. ${ }^{7,8}$ Despite the high stress levels, there is no study that has comprehensively studied all these factors in undergraduates studying first year of medical education in India.

With this background, the study aimed to assess perceived stress, coping, and burnout among first-year medical students.

\section{Methods}

The study design was that of a cross-sectional study. Hundred undergraduates pursuing first year of MBBS were enrolled into the study, during the month of November. Ethics approval was obtained from the Institutional Ethics Committee. Those who were present on the day of the study and who were willing to give consent were recruited. A semi-structured proforma assessing socio-demographic profile and the following tools were used for assessment of perceived stress, burnout, and coping.

Medical Students Stressor Questionnaire (MSSQ) was applied to assess perceived stress score. It is a 40 -item questionnaire assessing stress over 6 domains. It is a validated instrument to study stressors among medical undergraduates in India. Stress score is scored as mild (0-1), moderate (1.01-2), high (2.01-3), and severe (3.01-4). ${ }^{9}$

Burnout was studied by using Maslach burnout inventory-student survey, a 15-item instrument, validated in medical students. It assesses three areas of burnout: exhaustion (fatigue due to study), cynicism (pupil's psychological distance from studies), and professional efficacy (academic pursuit). The frequency related to each of these was rated on a Likert scale (from 0 to 6). Emotional exhaustion can be described as low (if score is less than or equal to 9), moderate (if score is between 10 and 14), and high (if score is greater than 14). Cynicism can be described as low (if score is less than or equal to 1 ), moderate (if score is between 2 and 6), and high (if score is greater than 6). Professional efficacy can be described as low (if score is less than or equal to 22), moderate (if score is between 23 and 27), and high (if score is greater than 28). ${ }^{10}$
As per two-dimensional criteria, burnout is diagnosed if greater emotional exhaustion and cynicism are present. As per three-dimensional criteria, burnout is diagnosed if greater emotional exhaustion, cynicism, and low professional efficacy are present. ${ }^{11}$

Coping was studied using Brief COPE questionnaire, which is a 28-item questionnaire validated in medical students. It assesses 14 domains, scored on a 4-point Likert scale. A higher score denotes greater use of particular coping strategies. ${ }^{12}$

\section{Statistical Analysis}

Descriptive statistics were analyzed. Student $t$-test was used to compare means for variables with normal distribution. Similarly, Mann-Whitney $U$ test was used for variables with nonnormal distribution, respectively. Tests of correlation were used to assess association. Statistical Package for the Social Sciences version 21.0 for Windows was used for analysis.

\section{Results}

All the 100 students took part in the study. There were 77 males and 23 females. The mean (standard deviation [SD]) age was $18.31(0.81)$ years and $77 \%$ of them were males. Majority belonged to an urban area (67\%) and nuclear family (63\%).

\section{Stress}

The mean cumulative stress score was significantly greater for the academic domain and was the least for the social-related stress. Majority of the students reported moderate levels of stress for the academic, intra- and interpersonal, teaching-learning, and group activity-related domains. Mild stress was perceived by most of the students in the social-related and drive- and desire-related domains (-Table 1).

\section{Burnout}

High emotional exhaustion and cynicism was found in 70\% and $79 \%$ students, respectively, and low professional efficacy in $44 \%$. Also, $62 \%$ were found to experience burnout as per two-dimensional criteria. In comparison, 30\% was found to have burnout as per three-dimensional criteria. The details of burnout scores are given in - Table 2.

\section{Coping}

Among problem-based coping and emotion-based coping, active coping and self-distraction were the most commonly used methods, respectively. With regard to least commonly used coping, instrumental support and drug use were reported in both the types of coping, respectively. The pattern of coping of students is given in - Table 3 .

\section{Correlation between Coping and Stress}

Significant weak correlation was obtained between emotion-focused coping and intrapersonal and interpersonal domain-related stress $(r=0.22 ; p=0.03)$, teaching and learning-related $(r=0.27 ; p=0.007)$, and social-related 
Table 1 Perceived stress among students

\begin{tabular}{|c|c|c|c|c|c|}
\hline \multirow[t]{2}{*}{ Stressor } & \multirow[t]{2}{*}{ Items } & \multicolumn{3}{|c|}{ Perceived stress $(n)$} & \multirow{2}{*}{$\begin{array}{l}\text { Mean stress } \\
\text { score }\end{array}$} \\
\hline & & Mild & Moderate & $\begin{array}{l}\text { High- } \\
\text { severe }\end{array}$ & \\
\hline \multirow{13}{*}{$\begin{array}{l}\text { Academic-related } \\
\text { stressor }^{9}\end{array}$} & Test/examination ${ }^{9}$ & 25 & 37 & 33 & 2.02 \\
\hline & Falling behind in reading schedule ${ }^{9}$ & 31 & 35 & 28 & 1.91 \\
\hline & Large amount of content to be learnt ${ }^{9}$ & 22 & 37 & 37 & 2.18 \\
\hline & Having difficulty in understanding the content ${ }^{9}$ & 36 & 27 & 23 & 1.67 \\
\hline & Getting poor marks ${ }^{9}$ & 23 & 20 & 48 & 2.24 \\
\hline & Quota system in examination ${ }^{9}$ & 22 & 19 & 25 & 1.47 \\
\hline & Paucity of time to revise ${ }^{9}$ & 32 & 27 & 44 & 1.88 \\
\hline & Need to do well (self-expectation) ${ }^{9}$ & 31 & 30 & 30 & 1.89 \\
\hline & Learning context: full of competition ${ }^{9}$ & 30 & 27 & 26 & 1.69 \\
\hline & Unable to answer the questions from the teachers ${ }^{9}$ & 28 & 25 & 28 & 1.73 \\
\hline & Heavy workload ${ }^{9}$ & 32 & 33 & 28 & 1.89 \\
\hline & Not enough medical skill practice ${ }^{9}$ & 0 & 0 & 0 & 0 \\
\hline & \multicolumn{4}{|c|}{ Mean cumulative stress score } & 1.71 \\
\hline \multirow{8}{*}{$\begin{array}{l}\text { Interpersonal-related } \\
\text { stressor }^{9}\end{array}$} & Conflicts with other students ${ }^{9}$ & 40 & 17 & 17 & 1.31 \\
\hline & Poor motivation to learn ${ }^{9}$ & 34 & 21 & 16 & 1.30 \\
\hline & Verbal or physical abuse by other students ${ }^{9}$ & 26 & 10 & 21 & 1.18 \\
\hline & Verbal or physical abuse by teachers ${ }^{9}$ & 19 & 18 & 37 & 1.82 \\
\hline & Verbal or physical abuse by personnel ${ }^{9}$ & 26 & 19 & 22 & 1.40 \\
\hline & ${\text { Conflict with personnel }{ }^{9}}^{9}$ & 41 & 25 & 10 & 1.27 \\
\hline & Conflict with teachers ${ }^{9}$ & 31 & 21 & 22 & 1.50 \\
\hline & \multicolumn{4}{|c|}{ Mean cumulative stress score } & 1.40 \\
\hline \multirow{8}{*}{$\begin{array}{l}\text { Teaching and learn- } \\
\text { ing-related stressor }\end{array}$} & Teacher: lack of teaching skills ${ }^{9}$ & 26 & 17 & 35 & 1.82 \\
\hline & Not enough study material ${ }^{9}$ & 24 & 14 & 41 & 0.90 \\
\hline & Inappropriate assignments ${ }^{9}$ & 39 & 32 & 18 & 1.61 \\
\hline & 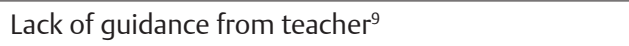 & 33 & 25 & 19 & 1.47 \\
\hline & Not enough feedback from teacher ${ }^{9}$ & 38 & 21 & 16 & 1.35 \\
\hline & Uncertainty of what is expected of $\mathrm{me}^{9}$ & 31 & 24 & 22 & 1.52 \\
\hline & Lack of recognition of work done ${ }^{9}$ & 33 & 20 & 26 & 1.58 \\
\hline & \multicolumn{4}{|c|}{ Mean cumulative stress score } & 1.46 \\
\hline \multirow{7}{*}{$\begin{array}{l}\text { Social-related } \\
\text { stressor }^{9}\end{array}$} & Lack of time for family and friends ${ }^{9}$ & 38 & 21 & 13 & 1.23 \\
\hline & Working with computers ${ }^{9}$ & 23 & 5 & 5 & 0.51 \\
\hline & Frequent interruption of my work by others ${ }^{9}$ & 30 & 31 & 25 & 1.73 \\
\hline & Unable to answer questions from patients ${ }^{9}$ & 0 & 0 & 0 & 0 \\
\hline & Taking to patients about personal problems ${ }^{9}$ & 0 & 0 & 0 & 0 \\
\hline & Facing illness or death of patients ${ }^{9}$ & 0 & 0 & 0 & 0 \\
\hline & \multicolumn{4}{|c|}{ Mean cumulative stress score } & 0.58 \\
\hline \multirow{4}{*}{$\begin{array}{l}\text { Drive- and desire-re- } \\
\text { lated stressor }{ }^{9}\end{array}$} & Unwillingness to study medicine ${ }^{9}$ & 26 & 14 & 20 & 1.24 \\
\hline & Parental wish for you to study medicine ${ }^{9}$ & 17 & 11 & 6 & 0.60 \\
\hline & Family responsibilities $^{9}$ & 30 & 19 & 7 & 0.93 \\
\hline & \multicolumn{4}{|c|}{ Mean cumulative stress score } & 0.92 \\
\hline \multirow{6}{*}{$\begin{array}{l}\text { Group activity-related } \\
\text { stressor }^{9}\end{array}$} & Participation in classroom discussion ${ }^{9}$ & 37 & 24 & 12 & 1.26 \\
\hline & Participation in classroom presentation ${ }^{9}$ & 39 & 20 & 16 & 1.30 \\
\hline & Need to do well (imposed by others) ${ }^{9}$ & 41 & 17 & 18 & 1.33 \\
\hline & Feeling of incompetence ${ }^{9}$ & 29 & 29 & 21 & 1.59 \\
\hline & Participation in classroom presentation ${ }^{9}$ & 39 & 20 & 16 & 1.30 \\
\hline & \multicolumn{4}{|c|}{ Mean cumulative stress score } & 1.37 \\
\hline
\end{tabular}


Table 2 Burnout among students

\begin{tabular}{|l|l|l|l|}
\hline Domain & Low (\%) & Moderate (\%) & High (\%) \\
\hline Emotional exhaustion & 13 & 17 & 70 \\
\hline Cynicism & 5 & 16 & 79 \\
\hline Professional efficacy & 38 & 18 & 44 \\
\hline
\end{tabular}

Table 3 Pattern of coping

\begin{tabular}{|c|c|c|c|c|}
\hline Coping type & Coping subscales & Items & Using commonly & Mean score \\
\hline \multirow{6}{*}{$\begin{array}{l}\text { Problem-based } \\
\text { coping }^{12}\end{array}$} & \multirow[t]{2}{*}{ Active coping ${ }^{12}$} & Focusing on working on the situation & 66 & 1.92 \\
\hline & & Working to improve the situation & 80 & 2.06 \\
\hline & \multirow[t]{2}{*}{ Using instrumental support ${ }^{12}$} & Seeking assistance & 60 & 1.62 \\
\hline & & Putting in efforts to seek assistance & 51 & 1.60 \\
\hline & \multirow[t]{2}{*}{ Planning ${ }^{12}$} & Putting in efforts to come up with a solution & 72 & 1.85 \\
\hline & & Contemplating further course of action & 70 & 1.94 \\
\hline \multirow{22}{*}{$\begin{array}{l}\text { Emotion-based } \\
\text { coping }^{12}\end{array}$} & \multirow[t]{2}{*}{ Self-distraction ${ }^{12}$} & Diverting oneself to other activities. & 72 & 1.83 \\
\hline & & $\begin{array}{l}\text { Doing something (movies, watching TV, } \\
\text { reading) to think less about it }\end{array}$ & 65 & 1.78 \\
\hline & \multirow[t]{2}{*}{ Denial $^{12}$} & Telling to oneself: "this is untrue" & 22 & 0.89 \\
\hline & & Denial of it happening & 23 & 0.83 \\
\hline & \multirow[t]{2}{*}{ Substance use ${ }^{12}$} & Drug or alcohol use to feel better & 5 & 0.18 \\
\hline & & Drug or alcohol use to move on & 5 & 0.17 \\
\hline & \multirow[t]{2}{*}{ Using emotional support ${ }^{12}$} & Getting emotional support from others & 35 & 1.29 \\
\hline & & Seeking solace from others & 53 & 1.72 \\
\hline & \multirow[t]{2}{*}{ Behavioral disengagement ${ }^{12}$} & Quitting efforts to work out the problem & 27 & 1.01 \\
\hline & & Quitting efforts to cope & 24 & 0.91 \\
\hline & \multirow[t]{2}{*}{ Self-blame $^{12}$} & Criticizing myself & 37 & 1.36 \\
\hline & & Self-reproach for the situation & 35 & 1.32 \\
\hline & \multirow[t]{2}{*}{ Venting $^{12}$} & $\begin{array}{l}\text { Venting out for letting out the obnoxious } \\
\text { feelings }\end{array}$ & 41 & 1.29 \\
\hline & & Communicating ill feelings & 35 & 1.23 \\
\hline & \multirow[t]{2}{*}{ Positive reframing ${ }^{12}$} & $\begin{array}{l}\text { Seeing in a different perspective to seek the } \\
\text { good side of the situation }\end{array}$ & 66 & 1.74 \\
\hline & & Trying to spot positives in the situation & 67 & 1.82 \\
\hline & \multirow[t]{2}{*}{ Humor $^{12}$} & Making jokes about it & 39 & 1.23 \\
\hline & & Making fun of the situation & 37 & 1.24 \\
\hline & \multirow[t]{2}{*}{ Acceptance $^{12}$} & Facing facts of the situation & 68 & 1.93 \\
\hline & & Learning to live with it & 56 & 1.51 \\
\hline & \multirow[t]{2}{*}{ Religion $^{12}$} & Turning to religion for feeling better & 50 & 1.34 \\
\hline & & Praying or meditating & 39 & 1.31 \\
\hline
\end{tabular}

stress $(r=0.23 ; p=0.023)$. However, significant weak correlation was obtained only between problem-focused coping and drive-related stress $(r=-0.32 ; p=<0.001)$.

Variations as Per Gender, Type of Family, and Residence Total stress scores, academic stress, intrapersonal and interpersonal stress, teaching and learning-related stress, and group activity-related stress, were significantly greater in females compared with males (-Table 4). Though there was no difference in the overall problem-focused and emotion-focused coping scores, females-mean $(\mathrm{SD})=2.30$ (0.82)-had significantly better active coping than males: mean $(\mathrm{SD})=1.80(0.93) ; t=-2.23 ; p=0.028$. There was no difference with regard to burnout.

Only academic-related stress was significantly higher in those residing in urban areas-mean $(S D)=23.69(7.93)-c o m-$ pared with those belonging to rural areas: mean $(\mathrm{SD})=19.33$ (8.05); $t=2.57 ; p=0.012$. No difference was found between any of the other stress scores, coping, and burnout with regard to type of family as well as place of residence. 
Table 4 Differences in stress, coping, and burnout as per gender

\begin{tabular}{|c|c|c|c|}
\hline \multirow[t]{2}{*}{ Domain } & Males $(n=77)$ & Females $(n=23)$ & \multirow[t]{2}{*}{$t$-Test $/ U$ test ( $p$-value) } \\
\hline & \multicolumn{2}{|c|}{ Mean (standard deviation) } & \\
\hline Academic-related stressor & $20.81(7.35)$ & $27.09(9.16)$ & $t=-3.39(p=0.001)^{\mathrm{a}}$ \\
\hline Intra- and interpersonal stress & $8.74(5.99)$ & $13.27(6.59)$ & $\begin{array}{l}U=537 \\
p=0.004 a\end{array}$ \\
\hline Teaching and learning-related stressor & $9.29(5.32)$ & $13.47(5.57)$ & $\begin{array}{l}U=517.50 \\
p=0.003 a\end{array}$ \\
\hline Social-related stressor & $3.34(2.07)$ & $3.91(1.93)$ & $\begin{array}{l}U=726.00 \\
p=0.185\end{array}$ \\
\hline Drive-related stressor & $2.84(2.53)$ & $2.52(2.31)$ & $\begin{array}{l}U=831.50 \\
p=0.654\end{array}$ \\
\hline Group activity-related stressor & $4.94(2.91)$ & $7.26(3.93)$ & $\begin{array}{l}U=564.00 \\
p=0.008 a\end{array}$ \\
\hline Total stress & $49.96(19.59)$ & $67.52(21.91)$ & $\begin{array}{l}U=487.00 \\
p=0.001 \mathrm{a}\end{array}$ \\
\hline Exhaustion & $18.47(6.40)$ & $17.61(6.70)$ & $t=0.56(p=0.57)$ \\
\hline Cynicism & $12.30(6.59)$ & $11.57(6.26)$ & $U=828(p=0.64)$ \\
\hline Professional efficacy & $25.84(6.44)$ & $24.34(7.77)$ & $t=0.93(p=0.35)$ \\
\hline Problem-focused coping & $10.75(2.91)$ & $11.78(2.61)$ & $t=-1.52(p=0.13)$ \\
\hline Emotion-focused coping & $27.78(7.76)$ & $28.43(7.13)$ & $t=-0.36(p=0.72)$ \\
\hline
\end{tabular}

${ }^{\mathrm{a}} p \leq 0.05$.

\section{Discussion}

The index study reported several important findings on perceived stress, coping, and burnout among first-year medical undergraduate students of an institute of national importance situated in northwestern India.

First, majority of students reported facing moderate level of stress in most of the domains, with stress being the highest for the academic aspects and least for social-related and drive- and desire-related areas. This is similar to various international as well as Indian studies where academic stress was the highest. ${ }^{13-20}$

However, there are few studies with varying results with regard to the severity of stress. The degree of any type of stress was mild in a study on first-year undergraduates from Mumbai. ${ }^{13}$ It is worthwhile to note that a study on medical trainees from Saudi Arabia found that $~ 58 \%$ students had no or mild stress. ${ }^{21}$ In an institute of national importance from Puducherry, it was found that $\sim 85 \%$ students had no or mild stress. ${ }^{22}$ Medical students from Florida, United States, reported higher severity of stress, with $\sim 68.9 \%$ of them finding it significant but manageable. ${ }^{23}$

Second, stress was higher among females compared with males. This is in concordance with several international as well as Indian studies, where academic stress was found to be greater in females compared with males. ${ }^{15,20,24,25}$ However, there are also studies where no difference was found. ${ }^{13,19,26}$ Stress related to conflict and pressures were higher in lady medical students compared with gents. ${ }^{27}$ An interesting point to note is that this was found to hold true across all the years of undergraduate medical education. A meta-analysis of nine Indian studies assessing stress found that males were at lesser odds of reporting stress (odds ratio $=0.9$ ) compared with females. ${ }^{28}$
Third, burnout could be identified in 62\% students by two-dimensional criteria and $30 \%$ by three-dimensional criteria. This is higher when compared with burnout in first-year medical undergraduates in Brazil, where it was $44.9 \%$ and $26.4 \%$, respectively. ${ }^{11}$ Also, $75 \%$ burnout was noted in preclinical medical students from Lebanon. ${ }^{29}$ Another difference noted was lower proportion of cynicism in Brazil (52.8\%) compared with our study (79\%). ${ }^{11}$ However, the rates of burnout with respect to emotional exhaustion and academic efficacy were similar in both the studies. ${ }^{11,29}$ A systematic review assessing 4,287 medical undergraduates reported the prevalence of burnout to be $\sim 50 \%{ }^{30}$

Fourthly, among coping strategies, active coping was most commonly used and substance use was less commonly used. This is similar to studies conducted in Nepal and India. ${ }^{13,25,31}$ They noted that planning, positive reframing, and active method of coping were the three most frequently employed strategies. Also, Chawla and Sachdeva ${ }^{13}$ found that substance use was the least commonly used method, as in our study. However, drugs were often used for coping in the United Kingdom. ${ }^{26,32-34}$

No differences were found in coping between males and females except for active coping, which was significantly better in females. This is contrast to several studies. Females were found to use emotion-focused coping more commonly than males. ${ }^{25,35}$ In another study, female undergraduates were found to use self-blame more commonly than males. ${ }^{27}$ Support seeking, both instrumental and emotional, was higher in third-year girl students compared with boys. ${ }^{25}$

Finally, only weak correlation was found between emotion-focused coping and intrapersonal and interpersonal domain-related stress, teaching and learning-related stress, and social-related stress, and between problem-focused 
coping and drive-related stress. Whereas a study from Kerala revealed that positive association was found between the following entities: academics with positive coping and religion; blame with academics, self-expectation and relationships; humor with self-expectations; living condition with health value conflict. ${ }^{36} \mathrm{~A}$ study from Ethiopia found that academic stress was associated with substance use. ${ }^{37}$

The differences obtained in our study could be due to variation in the instruments used to assess the study variables, and differences in study curriculum, year of medical education, teaching, as well as the socio-cultural differences. Several tools have been used for assessing stress such as perceived stress scale, MSSQ Depression Anxiety Stress Scale, and General Health Questionnaire. ${ }^{38}$ There are major differences in the structure of medical education in the West and the East. In comparison to the West, Indian medical education is reported to mostly focus on knowledge aspects in comparison to clinical skills and attitude, and assessment of the students is largely based on the subjective evaluation of the examiner. ${ }^{38}$ Furthermore, the Western method of teaching is largely integrated, that is, incorporating clinical exposure in the first year. ${ }^{39}$

Our study is probably the first study from India to comprehensively assess stress, burnout, and coping in undergraduate students pursuing first year of medical education using validated instruments. However, the study is bound by few limitations. The study findings might not be generalizable. It was a single-center study and had a small sample size. Personality, pattern of coping skills of students before joining the medical school, and history of psychiatric illness in self/family were not assessed. Furthermore, parameters such as exercise or sleep, which could have influenced the study findings, have not been assessed. Also, the study was conducted during November and first mid-term examination was conducted in October.

Nevertheless, the study has important implications. There is a need for development of stress management modules, specifically focusing on academic stress and females. Also, promotion of appropriate nonmaladaptive coping strategies is warranted. Finally, the study curriculum also needs to give adequate emphasis on the psychomotor and affective components of medical training to improve the mental health of medical undergraduates. In addition, there is a tremendous need for developing student-friendly stress clinics. We recommend assessment of stress, burnout, and coping at the intake of students into academic curriculum to understand their baseline status and, thereafter, conducting annual reassessments, while addressing the deficit areas. There is a need for future studies with bigger sample size and multicentric methodology for comparison of stress, burnout, and coping across academic centers with varying teaching and learning methods.

\section{Note}

The research has been performed conforming to the Declaration of Helsinki.

\section{Authors' Contributions}

N.N. conceptualized and conducted the study, gave intellectual input, and edited the manuscript. P.P.K. gave intellectual input, and wrote and edited the manuscript. M. conceptualized and conducted the study, gave intellectual input, and edited the manuscript. All the authors approved the manuscript.

\section{Funding}

None.

\section{Conflict of Interest}

None declared.

\section{References}

1 Dyrbye LN, Thomas MR, Shanafelt TD. Medical student distress: causes, consequences, and proposed solutions. Mayo Clin Proc 2005;80(12):1613-1622

2 Willcock SM, Daly MG, Tennant CC, Allard BJ. Burnout and psychiatric morbidity in new medical graduates. Med J Aust 2004;181(7):357-360

3 Bhagat V, Haque M, Simbak NB, Husain R. Stress among medical students and advantages of metallisation therapy in general: a review of literatures. Adv Hum Biol. 2018;8(2):59

4 Fares J, Al Tabosh H, Saadeddin Z, El Mouhayyar C, Aridi H. Stress, burnout and coping strategies in preclinical medical students. N Am J Med Sci 2016;8(2):75-81

5 Heinen I, Bullinger M, Kocalevent R-D. Perceived stress in first year medical students - associations with personal resources and emotional distress. BMC Med Educ 2017;17(1):4

6 Dunn LB, Iglewicz A, Moutier C. A conceptual model of medical student well-being: promoting resilience and preventing burnout. Acad Psychiatry 2008;32(1):44-53

7 Guruprakash KV, Mehta SG, Atul B, et al. A study of relationship between perceived stress, coping pattern, burnout, and general psychopathology among the postgraduate medical students. Ind Psychiatry J 2018;27(1):141-146

8 Singh S, Prakash J, Das RC, Srivastava K. A cross-sectional assessment of stress, coping, and burnout in the final-year medical undergraduate students. Ind Psychiatry J 2016;25(2):179-183

9 Yusoff MSB, Rahim AF, Yaacob MJ. The development and validity of the Medical Student Stressor Questionnaire (MSSQ) ASEAN J Psychiatry. 2010;11(1):1-12

10 Schaufeli WB, Martínez IM, Pinto AM, Salanova M, Bakker $A B$. Burnout and engagement in university students: a cross-national study. J Cross Cult Psychol 2002;33(5):464-481

11 Boni RADS, Paiva CE, de Oliveira MA, Lucchetti G, Fregnani JHTG, Paiva BSR. Burnout among medical students during the first years of undergraduate school: prevalence and associated factors. PLoS One 2018;13(3):e0191746

12 Carver CS. You want to measure coping but your protocol's too long: consider the brief COPE. Int J Behav Med 1997;4(1):92-100

13 Chawla K, Sachdeva V. Domains of stress and coping strategies used by 1 st year medical students. Natl J Physiol Pharm Pharmacol 2018;8(3):366-369

14 Eva EO, Islam MZ, Mosaddek ASM, et al. Prevalence of stress among medical students: a comparative study between public and private medical schools in Bangladesh. BMC Res Notes 2015;8:327

15 Ghosa K. Study on prevalence of stress in medical students. J Res Med Dent Sci. 2018;6(5):5 
16 Gupta S, Choudhury S, Das M, Mondol A, Pradhan R. Factors causing stress among students of a medical college in Kolkata, India. Educ Health (Abingdon) 2015;28(1):92-95

17 Shankar PR, Balasubramanium R, Ramireddy R, Diamante P, Barton B, Dwivedi NR. Stress and Coping Strategies among Premedical and Undergraduate Basic Science Medical Students in a Caribbean Medical School. Education in Medicine Journal 2014;6(4):e48-e56

18 Siraj HH, Salam A, Roslan R, Hasan NA, Jin TH, Othman MN. Stress and its association with the academic performance of undergraduate fourth year medical students at Universiti Kebangsaan Malaysia. International Med J Malays 2014;13(1):19-24

19 Supe AN. A study of stress in medical students at Seth G.S. Medical College. J Postgrad Med 1998;44(1):1-6

20 Surwase DK, Bagdey DP, Adikane DH. A cross sectional study of stress among medical students in Government Medical College, Nagpur [Internet]. 2016. Accessed June 27, 2020 at https://saspublisher.com/wp-content/uploads/2016/10/ SJAMS-49A-3229-3232.pdf

21 Abdulghani HM, AlKanhal AA, Mahmoud ES, Ponnamperuma GG, Alfaris EA. Stress and its effects on medical students: a cross-sectional study at a college of medicine in Saudi Arabia. J Health Popul Nutr 2011;29(5):516-522

22 Kumar SG, Kattimani S, Sarkar S, Kar SS. Prevalence of depression and its relation to stress level among medical students in Puducherry, India. Ind Psychiatry J 2017;26(1):86-90

23 Hill MR, Goicochea S, Merlo LJ. In their own words: stressors facing medical students in the millennial generation. Med Educ Online 2018;23(1):1530558

24 Backović DV, Zivojinović JI, Maksimović J, Maksimović M. Gender differences in academic stress and burnout among medical students in final years of education. Psychiatr Danub 2012;24(2):175-181

25 Madhyastha S, Latha KS, Kamath A. Stress, coping and gender differences in third year medical students. J Health Manag 2014;16(2):315-326

26 Firth J. Levels and sources of stress in medical students. Br Med J (Clin Res Ed) 1986;292(6529) :1177-1180

27 Sawant NS, Mishra K. Are medical students stressed out?: a study of gender differences and coping in undergraduates. Malays J Psychiatry 2015;24(1)
28 Sarkar S, Gupta R, Menon V. A systematic review of depression, anxiety, and stress among medical students in India. J Mental Health Hum Behav. 2017;22(2):88-96

29 Fares J, Saadeddin Z, Al Tabosh H, et al. Extracurricular activities associated with stress and burnout in preclinical medical students. J Epidemiol Glob Health 2016;6(3):177-185

30 Ishak W, Nikravesh R, Lederer S, Perry R, Ogunyemi D, Bernstein C. Burnout in medical students: a systematic review. Clin Teach 2013;10(4):242-245

31 Sreeramareddy CT, Shankar PR, Binu VS, Mukhopadhyay C, Ray B, Menezes RG. Psychological morbidity, sources of stress and coping strategies among undergraduate medical students of Nepal. BMC Med Educ 2007;7:26

32 Ashton CH, Kamali F. Personality, lifestyles, alcohol and drug consumption in a sample of British medical students. Med Educ 1995;29(3):187-192

33 Guthrie E, Black D, Bagalkote H, Shaw C, Campbell M, Creed F. Psychological stress and burnout in medical students: a five-year prospective longitudinal study. J R Soc Med 1998;91(5):237-243

34 Zvauya R, Oyebode F, Day EJ, Thomas CP, Jones LA. A comparison of stress levels, coping styles and psychological morbidity between graduate-entry and traditional undergraduate medical students during the first 2 years at a UK medical school. BMC Res Notes 2017;10(1):93

35 Eaton RJ, Bradley G. The role of gender and negative affectivity in stressor appraisal and coping selection. Int J Stress Manag 2008;15(1):94-115

36 Cherkil S, Gardens SJ, Soman DK. Coping styles and its association with sources of stress in undergraduate medical students. Indian J Psychol Med 2013;35(4):389-393

37 Melaku L, Mossie A, Negash A. Stress among medical students and its association with substance use and academic performance. J Biomed Edu 2015;2015p. e149509. Accessed January 24, 2021 at: https://www.hindawi.com/ journals/jbe/2015/149509/

38 Kulkarni P, Pushpalatha K, Bhat D. Medical education in India: past, present, and future. APIK J Intern Med. 2019;7(3):69

39 Venkatraman A, Nagpal SJ, Patel J. Systems of medical education in India and abroad: a comparison. Natl Med J India 2010;23(1):43-45 